\title{
FINISH MILLING STUDY OF Ti-6AI-4V PRODUCED BY LASER METAL DEPOSITION (LMD)
}

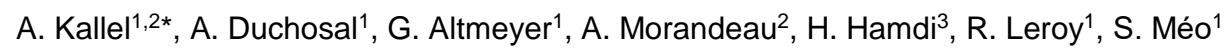 \\ ${ }^{1}$ Univ Tours, Univ Orléans, INSA CVL, LaMé, 7, Avenue Marcel Dassault 37200 Tours, France \\ ${ }^{2}$ Sandvik Tooling France - Division Coromant, Rue Henri Garih, 37230 Fondettes, France \\ 3Univ Lyon, ENISE, LTDS, 58 Rue Jean Parot, 42100 Saint Etienne, France \\ *Corresponding author; e-mail: achref.kallel@sandvik.com
}

\begin{abstract}
Components produced and repaired by the Laser Metal Deposition (LMD) process require finishmachining steps in order to improve the poor geometrical tolerance of the functional surfaces. In this work, the LMD process was conducted to build up samples from Ti-6Al-4V powders. The effect of the face milling process on surface roughness of the Ti-6Al-4V parts was studied in different build directions. The effect of the heat treatment was also considered. Changes in roughness and micro-hardness were evaluated and compared in each condition. Cutting forces were also measured in order to evaluate loading characteristic on the cutting insert. The heat-treated sample shows lower cutting forces in comparison with the as-build material. Different values of the surface roughness of the machined parts were obtained as a consequence of the microstructure variation.
\end{abstract}

\section{Keywords:}

Laser Metal Deposition (LMD); Milling; Ti-6Al-4V; Heat treatment; Surface integrity

\section{INTRODUCTION}

Laser Metal Deposition (LMD) is a well-employed additive manufacturing (AM) process to build complex near netshape and repair high-value parts. The process was first commercialized as Laser Engineered Net Shaping (LENS ${ }^{\mathrm{TM}}$ ) and developed by Sandia National Laboratory in 1993 [Atwood 1998]. The process gained more industrial interests thanks to its ability to produce massive components, high build rates, low porosity and competitive properties compared to the conventional material [Bi 2006]. Furthermore, the LMD process showed high capabilities of mixing multiple materials and repairing high value components [Hedges 2006]. This process is also able to build materials with high melting temperature, such as nickel-based and titanium alloys.

A special care needs to be addressed when producing components with qualification and certification requirements. Indeed, the produced parts by AM commonly require at least one post-processing [Blackmore 2010][Tian 2014] and surface finish operation [Formanoir 2016] to enhance the material properties and to satisfy the quality and tolerance of the surface. During the building process, Ti-6Al-4V parts undergo severe inhomogeneous cooling rates and cycles. This can lead to a difference in the microstructure and subsequently, in mechanical properties. Variation in the material properties and high anisotropy could appear even when similar building parameters are used [Zhao 2017]. Therefore, the machinability of the produced parts is expected to vary throughout the deposited structure.
Producing ready-to-use additive parts without the need of the post processing remains a big challenge for the $A M$ machine makers and users alike [Kianian 2018]. The additive parts are characterized by oxidized and unmelted particles, a staircase morphology, pores and lack of fusion [Li 2003]. This could affect material properties and the surface of the components.

A way to improve the material properties and to reduce material defects is to realize a Hot Isostatic Pressing (HIP) treatment [Thijs 2010]. A surface finish step is also required to fulfil the requirements of the functional surfaces especially when dimensional accuracy is expected. Hybrid machines are then developed allowing to merge AM and machining capabilities. These machines are capable of combining additive and subtractive processes of a metallic part within the same enclosure [Flynn 2016]. The interest of studying the machinability of the AM components is motivated by the development of new AM materials and applications and the need to understand the effect of post processing on the cutting operation. Nevertheless, the machining process of AM parts is less studied compared to the conventional ones. The term machinability could be defined as the ease or the difficulty of a material to be machined. The most used criteria to evaluate the machinability are the tool life, wear mechanism, cutting forces, surface integrity, cutting temperature and chip formation [Mills 1983].

The Ti-6Al-4V is one of the most investigated alloy in additive manufacturing domain due to its well compatibility with the majority of the AM processes and its large use in critical applications such as medical and aeronautical 
[Lütjering 1998]. This alloy is considered as a difficult to cut material as a result of its low thermal conductivity, high strain hardening effect, high elastic behaviour and high strength retained at high temperature.

The purpose of this work is to study the finish face milling process of Ti-6Al-4V produced by the LMD process. Three different components type were considered: a Ti-6Al-4V produced by the LMD process in the as-build condition, one after the HIP post-treatment and a conventional hot-rolled part. Furthermore, the milling process was performed in three different build directions as shown in Fig. 1. The effect of the AM build direction and the possible anisotropic properties of the AM parts on the cutting process could then be studied.

The cutting forces were measured and compared for each condition. The surface roughness was measured in order to compare the effect of the elaboration method on the surface finish of the machined part.

\section{EXPERIMENTAL METHODS}

The 5-axis Magic 800 machine designed by BeAM was used to build the LMD parts. It allows to build parts with a maximum build volume $(X, Y, Z)$ of $1200 \mathrm{~mm} \times 800 \mathrm{~mm} \times$ $800 \mathrm{~mm}$. The nozzle is mounted on the Z-axis of a CNC machine and is able to move in the three linear axis $(X, Y$ and $Z$ ) while the build platform rotates around two axis. The nozzle type is the MacroCLAD Head 24VX with a spot size equal to $2.25 \mathrm{~mm}$ having a laser as a heating source with a power of $1630 \mathrm{~W}$. The laser is a fibre doped Ytterbium with a wavelength equal to $1070 \mathrm{~nm}$. It is an YLS-2000 model from IPG LASER brand.

The nozzle is a coaxial combination of the laser source, the fed powder, a carrying gas and a secondary gas. The carrying gas allows the powder transportation, and the secondary gas is required to shape the powder jet at the output of the nozzle. The flowrates of the carrying and the shaping gases were $6 \mathrm{~L} / \mathrm{min}$ and $10 \mathrm{~L} / \mathrm{min}$ respectively. The scan speed is equal to $2000 \mathrm{~mm} / \mathrm{min}$ and the powder flowrate is $12 \mathrm{~g} / \mathrm{min}$. The atmosphere is controlled under argon gas to maintain an average $\mathrm{O}_{2}$ and $\mathrm{H}_{2} \mathrm{O}$ contents less than $1.5 \mathrm{ppm}$ and $70 \mathrm{ppm}$, respectively.

The powder used during this work is a gas atomized Ti-6Al$4 \mathrm{~V}$ grade 5 powder provided by AP\&C supplier. The diameter of the powder particles is $45-90 \mu \mathrm{m}$ and the chemical composition is presented in
Tab. 1.

Rectangular additive parts were build using the LMD process according to the Fig. 1 . The build strategy consists of a $180^{\circ}$ scanning tool path within each layer (in the $X$ and $Y$ directions) with and overlap spacing of $1.55 \mathrm{~mm}$. Once one layer is deposited, the nozzle moves in the $Z$ direction with an overlap $Z$ increment set to $0.8 \mathrm{~mm}$. 
Tab. 1: Ti-6Al-4V powder composition.

\begin{tabular}{cc}
\hline Elements & $\begin{array}{c}\text { LMD Ti-6Al-4V } \\
\text { Weight \% }\end{array}$ \\
Al & 6.42 \\
V & 4.01 \\
Fe & 0.2 \\
O & 0.14 \\
$\mathrm{C}$ & 0.02 \\
$\mathrm{~N}$ & 0.02 \\
$\mathrm{H}$ & 0.002 \\
$\mathrm{Y}$ & $<0.001$ \\
Other each. $\max$ & $<0.1$ \\
Other total. $\max$ & $<0.4$ \\
Ti & Balance \\
\hline
\end{tabular}

Rectangular specimens were produced with dimensions of $\mathrm{L}=60 \mathrm{~mm}, \mathrm{~h}=14 \mathrm{~mm}$ and $\mathrm{a}=12 \mathrm{~mm}$. The parts were manufactured in three different build directions as shown in Fig. 1. The samples were removed from the base plate using wire-EDM in order to avoid deforming and creating additional stress on the as-build material.

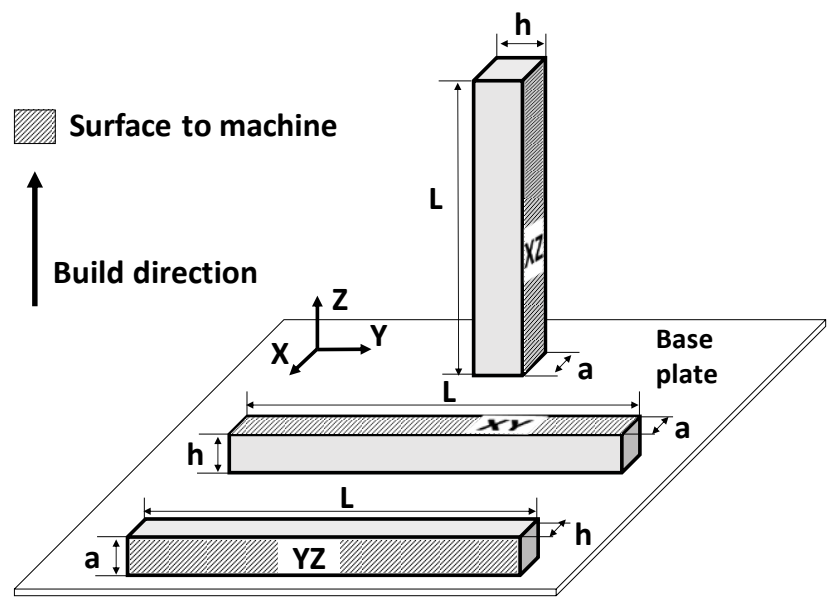

Fig. 1: Diagram of the build LMD parts.

In order to assess the effect of the heat treatment on the machining process, one sample was subjected to the Hot Isostatic Pressing (HIP) process. The heat treatment was conducted at a temperature of $920^{\circ} \mathrm{C}$ and a pressure of $102 \mathrm{MPa}$ maintained for 2 hours. The atmosphere was protected by the inert Argon gas. This provides a heat treatment and removes internal defects simultaneously. The combination of the heat and the pressure leads to a well-densified material with a homogenized microstructure.

The external faces were machined in order to have a radial engagement $\mathrm{a}=10 \mathrm{~mm}$ during the milling tests. A pre-pass of $0.5 \mathrm{~mm}$ were performed in each face to be machined in order to remove the external rough layers.

The face milling tests had been conducted on the Ti-6Al-4V parts obtained from the LMD and hot rolling processes. Concerning the additive samples, different faces were used to perform the machining process (Fig. 1). Different planes were machined with respect to the build direction as shown Fig. 1. The milling tool is a Coromill R300-035C3-10H with a cutting diameter equal to $25 \mathrm{~mm}$ supplied by Sandvik Coromant. One round insert with AITiN PVD coating (R3001032E-PL) was mounted on the tool holder. The cutting tool is centred with respect to the machined samples. In order to avoid the effect of changing the insert micro-geometry, the edge radius was controlled for each insert and kept in the range of $25 \pm 3 \mu \mathrm{m}$.

The depth of cut ap and the cutting speed $V_{c}$ were kept fixed at $0.5 \mathrm{~mm}$ and $55 \mathrm{~m} / \mathrm{min}$, respectively. A special clamping system was used to mount the samples on dynamometer KISTLER force sensor type 9255B (Fig. 2). Thanks to this mechanical clamping, cutting forces in three orthogonal axis were recorded. The resultant cutting force $R$ is adopted during this work and is calculated according to:

$R=\sqrt{F x^{2}+F y^{2}+F z^{2}}$

Where, Fx, Fy and Fz are the cutting, the radial and the axial forces, respectively, measured using the Kistler table in a fixed reference (Fig. 2).

In order to control the surface finishing quality, surface roughness $\mathrm{Ra}$ was measured using VEECO WYKO NT1100 optical profilometer. It is a contactless 3D surface profile measuring system based on laser interferometry.

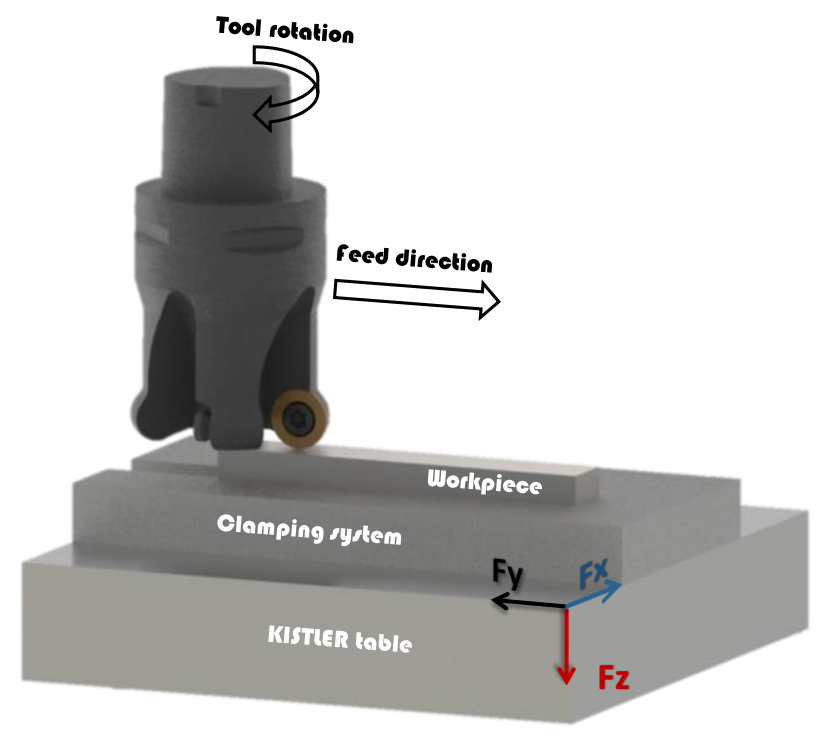

Fig. 2 : Diagram of the face-milling test.

\section{RESULTS}

\subsection{Clean-up steps of the external layers}

The additive manufacturing process produces parts with rough finished surface. The surface is characterized by staircase and wavy morphologies due to the layer-by-layer deposition and the laser scan pattern. This type of surfaces can promote crack initiation and thus needs to be machined. Subsequently, it is important to investigate the machining process of the outer layer. To this end, successive multi-passes of the external layers with a depth of cut of $0.5 \mathrm{~mm}$ and a feed $f_{z}=0.1 \mathrm{~mm} /$ tooth were performed and the cutting forces were recorded for each pass. An example of the resulted values for the HIPed material is presented in Fig. 3.

It was found that the cutting forces are higher when machining the external layer and decreases during removing the subsurface layers. The cutting force drops of about $38 \%$ at a depth of $1.5 \mathrm{~mm}$ compared to the one in the external surface. This depth corresponds to the minimum required material to be removed in order to reach a steady state of the cutting forces. This is mainly due to the variation in the microstructure and mechanical properties of the parts caused by the uncontrolled heating and cooling regimes 
during the building process. The same phenomenon is observed in the post-processed and as-build parts.

The results presented in the following sections are taken in the stable depth area in order to obtain consistent results and to minimize the effect of the surface variation.

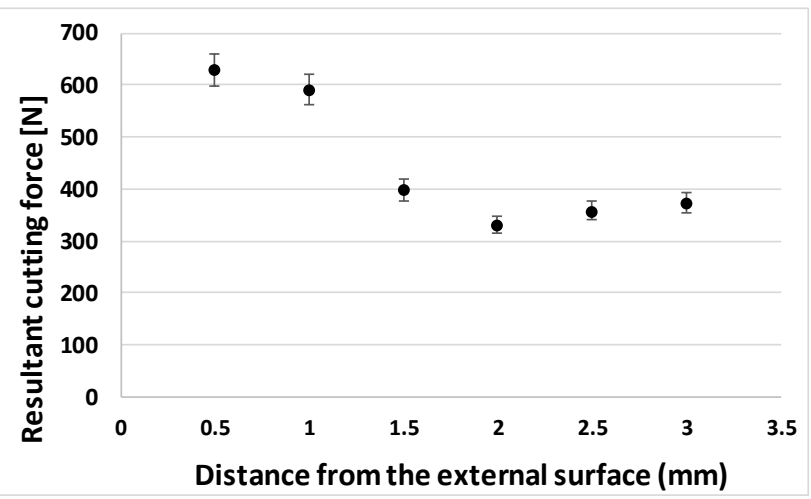

Fig. 3: Variation of the cutting forces $(f z=0.1 \mathrm{~mm} /$ tooth, ap $=0.5 \mathrm{~mm}, V_{C}=55 \mathrm{~m} / \mathrm{min}$ ) (Machined plane $X Z$ ).

\subsection{Effect of the heat treatment}

Machining tests were performed to assess the effect of different elaboration methods of the parts. Only the $Y Z$ plane is machined in this section and the cutting parameters are $f z=0.08 \mathrm{~mm} /$ tooth, $a p=0.5 \mathrm{~mm}$ and $V_{C}=55 \mathrm{~m} / \mathrm{min}$. Fig. 4 shows a comparison of the cutting forces for the asBuild, the heat-treated and the conventional machined samples.

On one hand, no changes in the cutting forces are observed between the heat-treated and conventional samples. On the other hand, Fig. 4 shows that higher forces of around $38 \%$ are generated for the as-build sample than the conventional and the HIPed ones. One possible explanation is the inhomogeneous microstructure of the asbuild parts and extensive porosity that could cause vibrations and instabilities during the cutting process. This inhomogeneity is reduced by HIP post processing [Thijs 2010] and it was also reported that the heat treatment reduces the AM material strength [Antolak-dudka 2019]. Another possible reason of this difference is the higher hardness values of the as-build LMD parts than those of the other samples as seen in Fig. 5. Indeed, the material produced in the as-build condition contains usually the martensitic $\alpha$ ' and fine $\alpha$ laths as a result of high cooling rates [Baufeld 2011]. The $\alpha$ ' phase and the fine laths lead to an increase in the hardness. The heat treatment allows a decomposition of the $\alpha$ ' into the $\alpha$ phase and an increase in the laths thickness which causes a reduction in the material hardness (Fig. 5).

For the LMD parts, the hardness seems to influence the cutting forces, since the as build material is machined with high cutting forces compared to the HIPed part (Fig. 4). In addition, the as build component present a high work hardening behaviour compared to the other samples as seen in Fig. 5. The variation of the cutting forces and in the material hardness will affect logically the tool-life and the surface integrity of the finished parts.

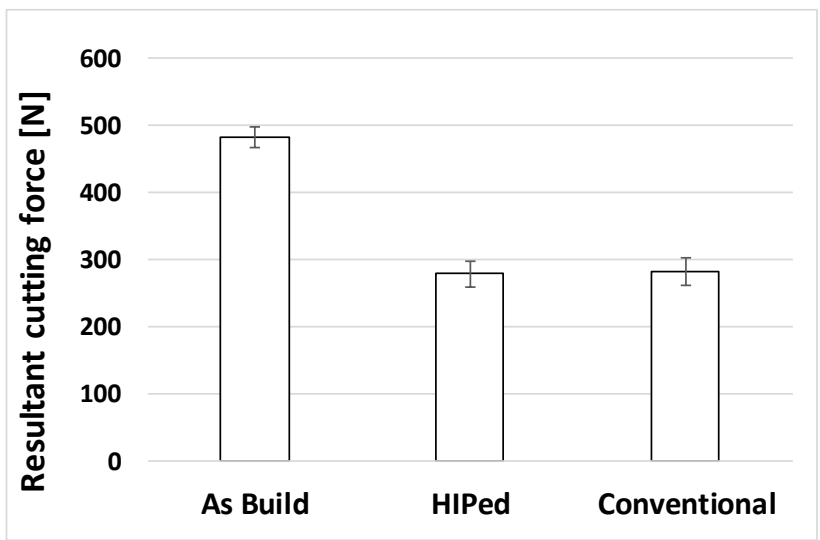

Fig. 4: Comparison of the cutting forces for the as-build, HIPed and Conventional Ti-6Al-4V $\left(f_{Z}=0.08 \mathrm{~mm} /\right.$ tooth, ap $=0.5 \mathrm{~mm}, V_{C}=55 \mathrm{~m} / \mathrm{min}$ ) (Machined plane $Y Z$ ).

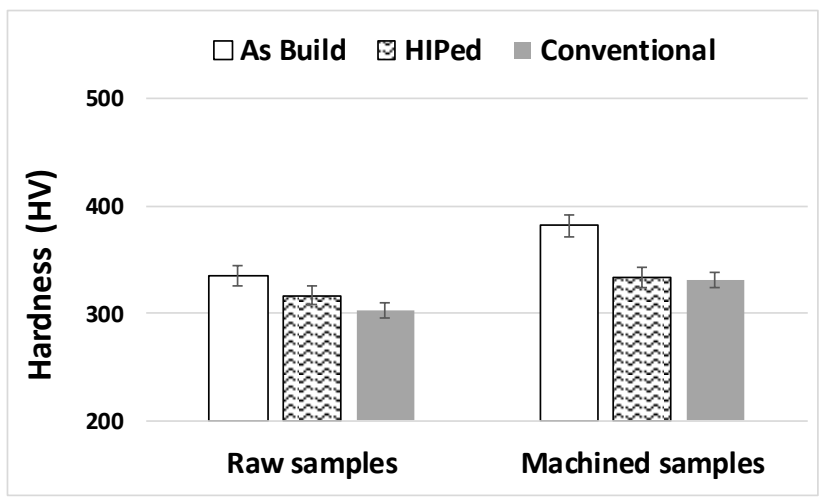

Fig. 5: Hardness values in the surface for the raw and machined samples.

The average surface roughness $R a$ of the LMD samples before the machining process was $7.5 \mu \mathrm{m}$ in the $Z$ direction and $25.5 \mu \mathrm{m}$ in the $X Y$ plane. The milling process produces parts with a surface roughness $\mathrm{Ra}$ between 0.26 and $0.354 \mu \mathrm{m}$. No significant variation in the surface roughness between the conventional and HIPed Ti-6AI-4V parts is observed.

Nevertheless, the conventional component presents $31 \%$ higher Ra value than the as-build one as shown in Fig. 6. This is a result of the difference in the microstructure and subsequently in mechanical behaviour. It was reported that hard material tends to produce low surface roughness values [Chen 2000][Nakayama 1988]. Indeed, during the tool pass, a plastic material flow occurs around the toolmaterial contact zone. The increase of this material flow leads to an increase in the peak to valley height and thus in surface roughness [Chen 2000]. The level of the plastic flow is higher for soft material and lower for hard material [Chen 2000]. Moreover, [Oishi 1995] suggests that by increasing the material hardness above a critical value, the build-up edge formed especially at low cutting and feed speeds, could be eliminated. As a result, the surface finish of the parts improves. This phenomenon was observed and investigated in the case of Selective Laser Melting (SLM) process where harder AM parts showed lower surface roughness than conventional material [Chlebus 2011].

The as-build LMD part has 10\% higher micro hardness values compared to the conventional material (Fig. 5). This could be a probable reason for the difference of the surface finish of the as-build LMD part compared to the HIPed and conventional ones. 


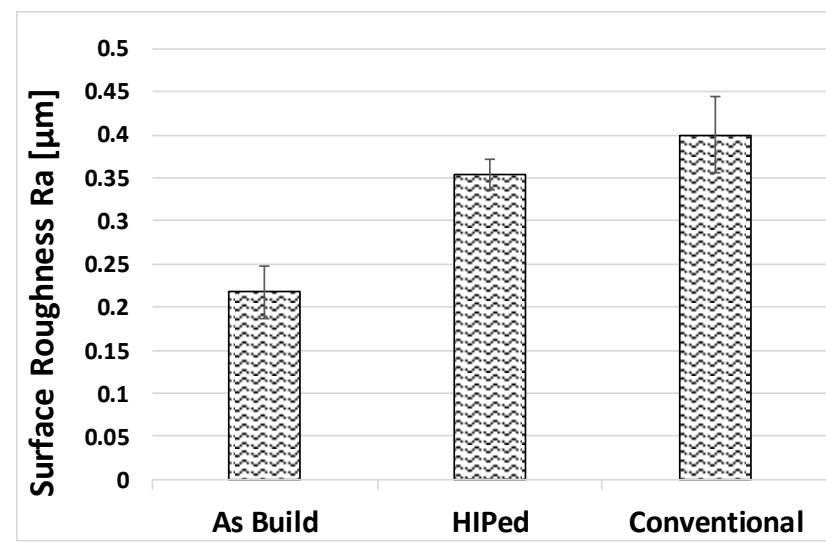

Fig. 6: Comparison of the surface roughness of different machined parts $\left(f_{z}=0.08 \mathrm{~mm} /\right.$ tooth, $a_{p}=0.5 \mathrm{~mm}, V_{C}=55$ $\mathrm{m} / \mathrm{min}$ ) (machined plane $Y Z$ ).

In addition, there is a variation in the minimum chip thickness necessary to have a cutting regime rather than ploughing regime depending on the material processing [Milton 2016]. Thus, there could be an interaction between the cutting parameters, the machining forces and the surface integrity depending on the material nature. It is thus important to determine the minimum chip thickness of each material.

\subsection{Effect of build direction}

Inhomogeneity of the microstructure and the strong anisotropy of the additive parts had been reported and widely discussed in literature [Thijs 2010][Baufeld 2011] [Kobryn 2001]. Indeed, the high thermal gradient in the build direction leads to a lower yield strength in the build direction than that in the $X$ and $Y$ directions [Kobryn 2001]. The microstructure and the material properties vary also depending on the build height as reported by [Baufeld 2011]. The possibility of a textured material [Neikter 2018] and the defect's presence [Chlebus 2011] could be a valid reason of this anisotropy. This could affect the cutting forces throughout the build parts.

In order to investigate the effect of the material anisotropy and inhomogeneity on the machining process, the milling operation was performed in three different planes of the HIPed LMD components: $X Y, X Z$ and $Y Z$ according to Fig. 1. The cutting forces were measured for each configuration as shown in Fig. 7. The results show that there is no significant variation in the cutting forces for different build direction on HIPed samples (5\%). This shows that the material texture has a small influence on the cutting forces and low anisotropic behaviour of the LMDed parts is expected.

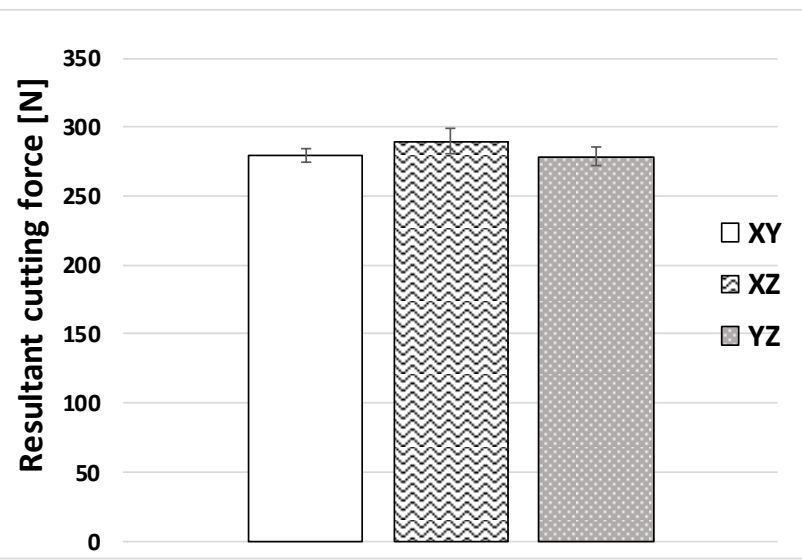

Fig. 7: Cutting force results for different machined planes ( $f_{z}=0.08 \mathrm{~mm} /$ tooth, $a_{p}=0.5 \mathrm{~mm}, V_{c}=55 \mathrm{~m} / \mathrm{min}$ ) (HIPed Sample).

Differences in the material properties and microstructure depending in the build location and height was reported [Kobryn 2001] [Baufeld 2011]. Indeed, the microstructure, the phase's composition and nature, and the material properties could vary significantly especially along the material height [Baufeld 2011]. This variation could affect the machinability of the LMDed parts as well as the final surface quality and the surface integrity.

In order to investigate the effect of the build direction on the surface finish, the surface roughness Ra resulted from the milling process performed in different directions of the HIPed samples was evaluated. Fig. 8 shows that the surface roughness is constant regardless of the machined plane with a maximum deviation of $3 \%$. The constant surface roughness values may be related to the HIP post process leading to a homogenization of the microstructure as explained in section 3.2.

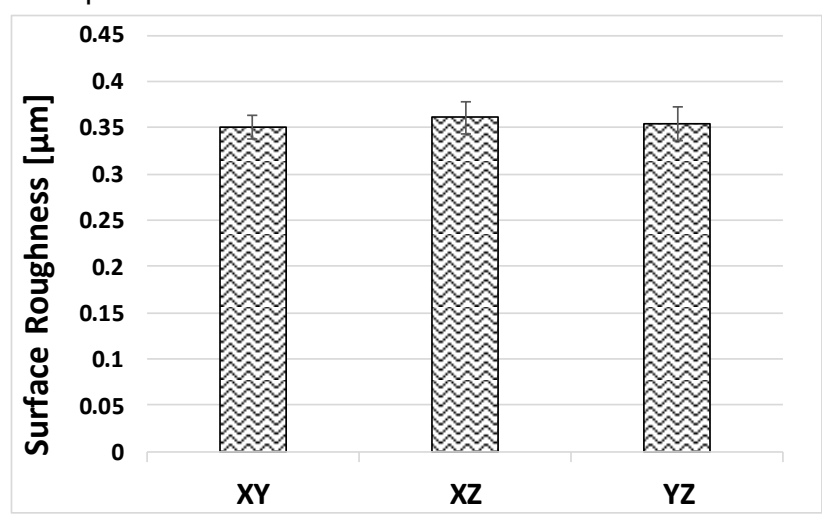

Fig. 8: Comparison of the Surface roughness Ra for different machined planes (HIPed samples).

\section{SUMMARY}

This work presented an experimental study of the machinability of the Ti-6Al-4V parts produced by the LMD process in order to understand the particularity of machining AM components compared to the conventional alloy. The following conclusions could be drawn as followed:

- The external surface of the AM parts presents a staircase and wavy morphologies resulting in a variation and high cutting forces. This layer (with a thickness of about 1.5 to $2 \mathrm{~mm}$ ) needs to be removed since it contains inhomogeneous microstructure and can act as a crack initiation sites. 
- The as-build LMDed part requires higher cutting forces as compared to the conventional and HIPed material. The HIP treatment reduces the machining forces as a result of a reduction of the hardness, internal defects and homogenization of the microstructure.

Different values of the surface roughness were obtained for the machined parts as a consequence of the hardness and microstructure variation.

Cutting forces and surface roughness show no significant variation with respect to the machined plane of the AM parts. The material texture has a small influence on the cutting process and low anisotropic behaviour of the LMDed parts is expected.

Further investigations on the residual stress and microstructure should be conducted in order to understand the effect of the cutting process on the surface integrity.

\section{ACKNOWLEDGMENTS}

The authors would like to thank the BeAM-France Company for providing the LMD-Ti-6AI-4V parts.

\section{REFERENCES}

[Antolak-dudka 2019] Antolak-dudka, Anna, Paweł Baranowski, and Paweł Bogusz. 2019. "Identification of Mechanical Properties for Titanium Alloy Ti-6Al-4V Produced Using LENS Technology." https://doi.org/10.3390/ma12060886.

[Atwood 1998] Atwood, Clint, Mark Ensz, Don Greene, Michelle Griffith, Lane Harwell, Daryl Reckaway, T Romero, Eric Schlienger, and John Smugeresky. 1998. "Laser Engineered Net Shaping (LENS(TM)): A Tool for Direct Fabrication of Metal Parts." In International Congress on Applications of Lasers \& Electro-Optics. https://doi.org/10.2351/1.5059147.

[Baufeld 2011] Baufeld, Bernd, Omer Van Der Biest, Rosemary Gault, and Keith Ridgway. 2011. "Manufacturing Ti-6Al-4V Components by Shaped Metal Deposition: Microstructure and Mechanical Properties." IOP Conference Series: Materials Science and Engineering 26 (1): S106-11. https://doi.org/10.1088/1757899X/26/1/012001.

[Baufeld 2011] Baufeld, Bernd, Erhard Brandl, and Omer Van Der Biest. 2011. "Journal of Materials Processing Technology Wire Based Additive Layer Manufacturing: Comparison of Microstructure and Mechanical Properties of $\mathrm{Ti}-6 \mathrm{Al}$ - 4V Components Fabricated by Laser-Beam Deposition and Shaped Metal Deposition." Journal of Materials Processing Tech. 211 (6): 1146-58. https://doi.org/10.1016/j.jmatprotec.2011.01.018.

[Bi 2006] Bi, Guijun, Andres Gasser, Konrad Wissenbach, Alexander Drenker, and Reinhart Poprawe. 2006. "Characterization of the Process Control for the Direct Laser Metallic Powder Deposition." Surface and Coatings Technology $201 \quad$ (6): 2676-83. https://doi.org/10.1016/j.surfcoat.2006.05.006.

[Blackmore 2010] Blackmore, M L, W Zhang, and I Todd. 2010. "The Origin of Microstructural Diversity, Texture, and Mechanical Properties in Electron Beam Melted Ti-6AI-4V." https://doi.org/10.1007/s11661-010-0397-x.

[Chen 2000] Chen, Wuyi. 2000. "Cutting Forces and Surface Finish When Machining Medium Hardness Steel Using CBN Tools" 40: 455-66.
[Chlebus 2011] Chlebus, Edward, Bogumiła Kuźnicka, Tomasz Kurzynowski, and Bogdan Dybala. 2011. "Microstructure and Mechanical Behaviour of $\mathrm{Ti}-6 \mathrm{Al}-7 \mathrm{Nb}$ Alloy Produced by Selective Laser Melting." Materials Characterization 62: 488-495. https://doi.org/10.1016/j.matchar.2011.03.006

[Flynn 2016] Flynn, Joseph M, Alborz Shokrani, Stephen T Newman, and Vimal Dhokia. 2016. "Hybrid Additive and Subtractive Machine Tools - Research and Industrial Developments." International Journal of Machine Tools and Manufacture 101: 79-101. https://doi.org/10.1016/j.ijmachtools.2015.11.007.

[Formanoir 2016] Formanoir, Charlotte De, Sébastien Michotte, Olivier Rigo, and Lionel Germain. 2016. "Electron Beam Melted $\mathrm{Ti}-6 \mathrm{Al}-4 \mathrm{~V}$ : Microstructure, Texture and Mechanical Behavior of the as-Built and Heat-Treated Material." Materials Science \& Engineering A, 652: 105-19. https://doi.org/10.1016/j.msea.2015.11.052.

[Hedges 2018] Hedges, Martin, and Neil Calder. 2006. "Near Net Shape Rapid Manufacture \& Repair by LENS $\square$." [Kianian 2018] Kianian, Babak. 2018. "Wohlers Report 2019 3D Printing and Additive Manufacturing State of the Industry."

[Kobryn 2001] Kobryn, P A, and S L Semiatin. 2001. "The Laser Additive Manufacture of Ti-6Al-4V," no. September: 40-42.

[Li 2003] Li, Yanmin, Haiou Yang, Xin Lin, Weidong Huang, and Jianguo Li. 2003. "The Influences of Processing Parameters on Forming Characterizations during Laser Rapid Forming" 360: 18-25. https://doi.org/10.1016/S09215093 (03) 00435-0.

[Lütjering 1998] Lütjering, G. 1998. "Influence of Processing on Microstructure and Mechanical Properties of $(A+\beta)$ Titanium Alloys." Materials Science and Engineering: A 243 (1-2): 32-45. https://doi.org/10.1016/S0921-5093 (97) 00778-8.

[Mills 1983] Mills, B, and A H. Redford. 1983. "The Concept of Machinability." In Machinability of Engineering Materials, 1-3. https://doi.org/10.1007/978-94-009-6631-4_1.

[Milton 2016] Morandeau, F. Chalon, and R. Leroy. 2016. "Comparative Study on Machinability of Ti6Al4V Produced by Selective Laser Melting and Electron Beam Melting." In Thirteenth International Conference on HIGH SPEED MACHINING 2016.

[Nakayama 1988] Nakayama, Kazuo, Masataka Arai, and Torahiko Kanda. 1988. "Machining Characteristics of Hard Materials." Cirp Annals-Manufacturing Technology - CIRP ANN-MANUF TECHNOL 37: 89-92. https://doi.org/10.1016/S0007-8506 (07)61592-3.

[Neikter 2018] Neikter, M, R Woracek, Tuerdi Maimaitiyili, Ch Scheffzük, Markus Strobl, Marta-Lena Antti, Pia Åkerfeldt, Robert Pederson, and Christina Bjerkén. 2018. "Alpha Texture Variations in Additive Manufactured Ti-6Al4V Investigated with Neutron Diffraction." Additive Manufacturing https://doi.org/10.1016/j.addma.2018.08.018.

[Oishi 1995] Oishi, K. 1995. "Built-up Edge Elimination in Mirror Cutting of Hardened Steel." Journal of Engineering for Industry 117. https://doi.org/10.1115/1.2803279.

[Thijs 2010] Thijs, Lore, Frederik Verhaeghe, Tom Craeghs, Jan Van Humbeeck, and Jean-pierre Kruth. 2010. "A Study of the Microstructural Evolution during Selective Laser Melting of $\mathrm{Ti}-6 \mathrm{Al}-4 \mathrm{~V}$." Acta Materialia 58 (9): 3303-12. https://doi.org/10.1016/j.actamat.2010.02.004. 
[Tian 2014] Tian, X J, S Q Zhang, and H M Wang. 2014. "The Influences of Anneal Temperature and Cooling Rate on Microstructure and Tensile Properties of Laser Deposited Ti - 4Al - 1. 5Mn Titanium Alloy." JOURNAL OF ALLOYS AND COMPOUNDS 608: 95-101. https://doi.org/10.1016/j.jallcom.2014.04.058.

[Zhao 2017] Zhao, Zhuang, Jing Chen, Xufei Lu, Hua Tan, Xin Lin, and Weidong Huang. 2017. "A Formation
Mechanism of the $\alpha$ Variant and Its influence on the Tensile Properties of Laser Solid Formed Ti-6Al-4V Titanium Alloy." Materials Science \& Engineering A 691 (March): 16-24. https://doi.org/10.1016/j.msea.2017.03.035. 